\title{
Vecuronium Requirement By Continuous Infusion Technique In Adult Patients During Fentanyl Nitrous Oxide - Oxygen Anesthesia.
}

\author{
Dr Shraddha Mathkar ${ }^{1}$,Aarti Kulkarni ${ }^{2}$,Late Dr Jaitly ${ }^{3}$ \\ ${ }^{1}$ (Anesthesiology, Gsmc\&Kemh/Muhs, India) \\ ${ }^{2}$ (Anesthesiology, Gsmc\&Kemh/Muhs, India)
}

\begin{abstract}
Good relaxation is required in abdominal surgeries. Continuous infusion of nondepolarizing neuromuscular blocking agents with TOF monitoring helps to maintain constant serum levels and a stable paralysis state. We conducted an observational study in 50 ASA I and II patients, between 18-65 years undergoing elective abdominal surgeries after ethics committee approval.
\end{abstract} Aims And Objectives: Dose of Vecuronium required by continuous infusion. Spontaneous recovery time, quality of muscle relaxation .

Material methods: Informed consent was taken. Induction done with Inj. thiopentone, Inj. Succinylcholine and vecuronium $100 \mu \mathrm{g} / \mathrm{kg}$. Vecuronium infusion @ $50 \mu \mathrm{g} / \mathrm{kg} / \mathrm{hr}$ was started at TOF-1 and maintained by titrating the infusion @ $5 \mu \mathrm{g} / \mathrm{kg} / \mathrm{hr}$. Anesthesia was maintained with Nitrous oxide (70\%) \& Oxygen (30\%). At closure of rectus sheath, infusion was stopped. Patient reversed with TOF-3 and confirmation of sustained head lift and hand grip and then extubated.

Results: The infusion dose was $62.79 \pm 5.631 \mu \mathrm{g} / \mathrm{kg} / \mathrm{hr}$, dose required in age group > 61 years $(56.43 \pm 8.13$ $\mu \mathrm{g} / \mathrm{kg} / \mathrm{hr})$ is less than $<40$ years $(63.77 \pm 5.86 \mu \mathrm{g} / \mathrm{kg} / \mathrm{hr})$. The mean recovery time is $12.4 \pm 3.63$ minutes. Conclusion: Continuous infusion technique of Vecuronium provides an adequate level of relaxation, hemodynamic stability and prompt recovery.

Keywords : Abdominal surgery, continuous infusion, Relaxation, TOF .vecuronium,.

\section{Introduction}

During laparotomy, surgeons frequently experience difficult surgical conditions if the patient's abdominal wall or diaphragm is tense ${ }^{1}$. Saverse and $\mathrm{Kitz}^{2}$ in 1975, described characteristics of an ideal muscle relaxant. The lack of cardiovascular effects of vecuronium established a benchmark for safety to which newer muscle relaxants are still held, so it still enjoys popularity in day to day practice ${ }^{3 .}$ Stable neuromuscular blockade can be achieved rapidly with infusion of vecuronium and blockade can be quickly and easily antagonized following even prolong vecuronium infusion. Neuromuscular monitoring aids in assessing the relaxation during intubation, maintenance and reversal of anaesthesia. In 2010 clinical guidelines "When neuromuscular blocking drugs are given, the use of a peripheral nerve stimulator is recommended ${ }^{5}$. Theoretical advantage of continuous infusion over intermittent bolus injection includes fewer period of poor anaesthesia control, a reduction in total amount of drug used and, more rapid recovery from anaesthesia ${ }^{6,7}$. Delayed recovery and cumulation has been the impedance for continuous infusion of muscle relaxants.

Pharmacokinetics and pharmacodynamics of vecuronium is affected by multiple factors like age, sex, temperature etc. In our observation study, we have tried to quantify the dose of vecuronium needed by continuous infusion after a loading dose in elective abdominal surgeries, the time needed for recovery, the adequacy of relaxation, hemodynamics and complication if any during anesthesia.

\section{Material And Methods}

50 patients of ASA I and II physical status, between 18 to 65 years undergoing elective abdominal surgeries were enrolled in our prospective observational study after ethics committee approval. Patients with liver, kidney neurorneuromuscular disease, extensive malignancy and active foci of infections were excluded. History of intake of drug affecting neuromuscular blockade like aminoglycosides was ruled out.

Starvation and written informed consent noted. Peripheral nerve stimulator (the Neuromuscular monitoring device used was TOF Guard, Organonon Teknika. NV) was positioned on the ulnar nerve over the volar side of the wrist. visible TOF response was noted every 3 minutes intraoperatively. All patients were premedicated with intravenous Inj. diazepam $0.1 \mathrm{mg} / \mathrm{kg}$ and fentanyl $2 \mu \mathrm{g} / \mathrm{kg}$ before induction. Induction was carried out with Inj. Thiopentone 4-6 mg/kg titrated. Supramaximal stimulus with single twitch was recorded. After confirming adequacy of ventilation, Inj. Succinylcholine $1.8 \mathrm{mg} / \mathrm{kg}$ was administered. Patient was intubated. Loading dose of Vecuronium $100 \mu \mathrm{g} / \mathrm{kg}$ intravenously was given. Anesthesia was maintained with 
Nitrous oxide $(70 \%)+$ Oxygen $(30 \%)$. Inj. Fentanyl $1 \mu \mathrm{g} / \mathrm{kg}$ was repeated every 40 minutes and intermittently so as to maintain hemodynamic stability.

Patient's temperature was maintained between $35.5^{\circ} \mathrm{C}$ to $37^{\circ} \mathrm{C}$. and intraoperative normocarbia (Endtidal $\mathrm{CO}_{2}$ between $32-37 \mathrm{mmHg}$ ). The neuromuscular monitoring was done throughout the surgery using a Peripheral Nerve Stimulator, and a. After recovery to TOF-1, an infusion of vecuronium was started using an infusion pump at the rate of $50 \mu \mathrm{g} / \mathrm{kg} / \mathrm{hr}$ and titrated at the rate of $5 \mu \mathrm{g} / \mathrm{kg} / \mathrm{hr}$, to maintain a stable state of paralysis at TOF-1 during the surgery. After closure of the muscle layer and sheath, vecuronium infusion was stopped. With the return of TOF count 3, was done with Inj. Neostigmine $0.05 \mathrm{mg} / \mathrm{kg}$ and Inj. Glycopyrolate 8 $\mu \mathrm{g} / \mathrm{kg}$.. Awakefulness, return of pharyngeal reflexes and adequate tone, patient was extubated after thorough oral suction and post-oxygenated for with $100 \%$ oxygen. Hemodynamics were monitored throughout the surgery. $20 \%$ rise from mean baseline of the preoperative values of heart rate and blood pressure will be considered as significant tachycardia and hypertension treated with additional dose of fentanyl $1 \mu \mathrm{g} / \mathrm{kg}$ initially if untreated other modalities (inhalational agents, antihypertensives) were used and patient were discarded from the study.

The total dose of vecuronium infused was noted. The dose required for stable paralysis in $\mu \mathrm{g} / \mathrm{kg} / \mathrm{hr}$ will be calculated. Recovery time, defined as time from termination of vecuronium infusion till appearance of TOF count of 3 was noted.The operating surgeon will judge the muscle relaxation in to adequate, good, poor depending upon the retraction required by them during the surgery. Statistical Analysis : Results were expressed as mean values \pm standard deviation. $P$ values for mean values were calculated using Student's ' $t$ ' test. Pearson's correlation coefficient were calculated wherever applicable. Results were considered statistically significant at the 'p' at 0.05 level.

\section{Results}

The mean age of patients study was $46.22 \pm 9.37$ years. 5 patients were above 60 years. 38 females and 12 males in the study and not comparable. ASA $1-56 \%$ and ASA II $44 \%$, mostly were controlled hypertension and DM. The mean weight was $64.07 \pm 9.15 \mathrm{~kg}$, maximum weight was $88 \mathrm{~kg}$. The mean dose required to maintain a stable paralysis by continuous infusion technique was $62.79 \pm 5.63 \mu \mathrm{g} / \mathrm{kg} / \mathrm{hr}$. Patients below 40 years needed $63.77 \pm 5.86 \mu \mathrm{g} / \mathrm{kg} / \mathrm{hr}, 40-60$ years age group patients was $63.40 \pm 4.64 \mu \mathrm{g} / \mathrm{kg} / \mathrm{hr}$ almost comparable with below 40 years. The dose requirement is least in patients above 60 years it is $56.43 \pm 8.13$ $\mu \mathrm{g} / \mathrm{kg} / \mathrm{hr}$.(Figure-1)The mean duration of vecuronium infusion was $88.28 \pm 28.65$ minutes. 36 cases were in range of 50-100 minutes of the infusion

The heart rate and bloodpressure was monitored every $5 \mathrm{~min}$. The mean change from the preinduction values were studied. There was mean change of $3 \pm 3.84$ /minute from the preinduction heart rate, the mean preinduction heart rate was $68.94 \pm 7.07 /$ minute and the mean intraoperative heart rate was $71.94 \pm$ $6.93 /$ minute. The mean preinduction systolic blood pressure was $131.72 \pm 8.45 \mathrm{mmHg}$ while the mean intraoperative systolic blood pressure was $136.37 \pm 9.22 \mathrm{mmHg}$ and the mean difference was $4.66 \pm 5.43 \mathrm{mmHg}$. The mean preinduction diastolic blood pressure was $79.58 \pm 5.43 \mathrm{mmHg}$ while the mean intraoperative diastolic blood pressure was $82.21 \pm 5.10 \mathrm{mmHg}$ with a mean change of $2.54 \pm 3.68 \mathrm{mmHg}$. There was increase in the heart rate, systolic blood pressure, and diastolic blood pressure at intubation and initial period of starting infusion and latter the vitals paralleled the preinduction values. The $\mathrm{p}$ values are calculated in comparison with the preinduction values, @ p value $<0.05$ significant. The significant difference cannot be calculated at 150 and 165 minutes of infusion as sample size was one. The variability the data at 150 and 165 minutes may be due to thinning of the sample size. . $p$ valve of heart rate from 15 minutes from starting of infusion is $p=0.127$, at 30 , $45,60,105,120,135$, they are $\mathrm{p}=0.120, \mathrm{p}=0.534, \mathrm{p}=0.301, \mathrm{p}=0.85, \mathrm{p}=0.159, \mathrm{p}=0.820, \mathrm{p}=0.675$, and $p=0.761$ respectively. The systolic blood pressure $p$ values at $30,45,60,75,90,105,120$, and 135 minutes are $\mathrm{p}=0.65, \mathrm{p}=0.45, \mathrm{p}=0.35, \mathrm{p}=0.44 \mathrm{p}=0.23, \mathrm{p}=0.54, \mathrm{p}=0.63$, and $\mathrm{p}=0.22$ respectively. The diatolic bloodpressure, $\mathrm{p}$ values at $30,45,60,75,90,105,120$, and 135 minutes are $0.35,0.32,0.87,0.82,0.19,0.06$, $0.31,0.29$, and 0.30 respectively(Figure-2,3)

There is significant difference during intubation, TOF- 1 , and reversal in heart rate, systolic blood pressure and diastolic blood pressure. There is no is significant difference during vecuronium infusion in the heart rate in comparison with the preinduction heart rate. There is significant difference in systolic blood pressure and diastolic blood pressure at 15 minutes from starting of vecuronium infusion. The variability in heart rate, systolic blood pressure and diastolic blood pressure becomes insignificant from 30 minutes till end of infusion. The mean recovery time was $12.4 \pm 3.63$ minutes. The minimum time of spontaneous recovery was 7 minutes and the maximum time was 28 minutes. The maximum $30 \%$ patients fall in range of 5-11 minutes and $54 \%$ are in 11-15 minutes(Figure-4). The correlation between Recovery time and dose ( $\mathrm{mg} / \mathrm{kg} / \mathrm{hr}$ ) is -0.125 and it is not significant as $\mathrm{p}>0.05$ (i.e., 0.386 ). The correlation between Recovery time and duration of infusion is 0.36 (Figure-5)and it is significant as $\mathrm{p}>0.05$ (i.e., 0.02). . Maximum 54\% patients fall in good category. Only $6 \%$ patients in poor category. $40 \%$ had adequate relaxation.(Figure-6) 


\section{Discussion}

Use of muscle relaxants not only revolutionized the practice of anesthesia but also started the modern era of surgery and made possible the explosive development of cardiothoracic, neurologic and organ transplant surgery, as stated by Foldes and co-authors ${ }^{8}$. Vecuronium is an intermediate-acting drug with an onset time of 2-3 minutes acting for around $22 \pm 2$ minutes. Efficient titration by continuous infusion will lead to use of lesser drug, will maintain stable paralysis state, minimize the adverse effects and allow a rapid recovery on termination of the drug. The only drawback is cumulative effect in prolonged infusion of drug if given in large doses. Eriksson LI, et $\mathrm{al}^{9}$ and Mirakhur RK, et $\mathrm{al}^{10}$ showed no cumulation occurs with vecuronium. that prompt recovery occurs without any cumulative effect 50 Patients between 18-65 years were selected, the dose requirement of vecuronium varies with the age group. Figure-1

\begin{tabular}{|c|c|}
\hline Age (years) & Dose required (our) \\
\hline$<40$ & $63.77 \pm 5.86 \mu \mathrm{g} / \mathrm{kg} / \mathrm{hr}(\mathrm{n}$ \\
\hline $6-60$ & $63.40 \pm 4.64 \mu \mathrm{g} / \mathrm{kg} / \mathrm{hr}(\mathrm{n}$ \\
\hline 60 & $56.43+8.13 \mu \mathrm{g} / \mathrm{kg} / \mathrm{hr}(\mathrm{n}=5)$ \\
\hline
\end{tabular}

$$
\begin{array}{r}
\text { Dose required (Hollander) } \\
67.8 \pm 10.8 \mu \mathrm{g} / \mathrm{kg} / \mathrm{hr}(\mathrm{n}=8) \\
65.4 \pm 7.8 \mu \mathrm{g} / \mathrm{kg} / \mathrm{hr}(\mathrm{n}=8) \\
43.2 \pm 5.4 \mu \mathrm{g} / \mathrm{kg} / \mathrm{hr}(\mathrm{n}=8)
\end{array}
$$

d'Hollander $\mathrm{A}$, et $\mathrm{al}^{11}$ in their age dependant dose response relationship study noted requirement of vecuronium for age groups were as follows, The vecuronium requirement in our study (Figure-1) in age groups $<40$ years and 40-60 years parallels the results in d'Hollander study. The dose needed in age group > 60 years is less than patients of $<60$ years in both studies. Cynthia A Lien, et al ${ }^{12}$ concluded that an anesthetist should expect the action of vecuronium to be prolonged in elderly surgical patients

The mean maintenance dose given by infusion to maintain a stable paralysis in our study was $62.79 \pm$ $5.63 \mu \mathrm{g} / \mathrm{kg} / \mathrm{hr}$ (Figure-1). The average infusion of dose of vecuronium by infusion nearly equates the dose calculated by Chaudhari LS, et $\mathrm{al}^{13}(63.2 \pm 74 \mu \mathrm{g} / \mathrm{kg} / \mathrm{hr})$, but less than as found by HH Ali, et al ${ }^{14}(72 \mu \mathrm{g} / \mathrm{kg} / \mathrm{hr})$, but more than J Swen, et $\mathrm{al}^{15}(47.6 \pm 9.7 \mu \mathrm{g} / \mathrm{kg} / \mathrm{hr})$. Chaudhari LS, et al ${ }^{13}$, observed that the dose of vecuronium given by continuous infusion to maintain a stable paralysis was $63.2 \pm 74 \mu \mathrm{g} / \mathrm{kg} / \mathrm{hr}$ in para median and midline abdominal surgeries. $\mathrm{N}_{2} \mathrm{O}+\mathrm{O}_{2}+$ pentazocin was used for maintenance of anesthesia. $\mathrm{HH} \mathrm{Ali}$, et al ${ }^{14}$ showed the average infusion rate of vecuronium for maintenance of 90-99\% twitch depression was $72 \mu \mathrm{g} / \mathrm{kg} / \mathrm{hr}$ in $\mathrm{N}_{2} \mathrm{O}+\mathrm{O}_{2}$ + Fentanyl $(4-8 \mu \mathrm{g} / \mathrm{kg})$ anesthesia. While J Swen, et $\mathrm{al}^{15}$ showed that for $90 \%$ reduction of twitch force, dose required is $47.6 \pm 9.7 \mu \mathrm{g} / \mathrm{kg} / \mathrm{hr}$. Halothane + Fentanyl $(3-8 \mu \mathrm{g} / \mathrm{kg})$ was used for maintenance.

Cannon JE, et $\mathrm{al}^{[4]}$ noted the dose of vecuronium infusion with inhalational anesthetic agents and compared with fentanyl anesthesia. This concludes that dose required of vecuronium is decreased with inhalational agents. Hence, no volatile anesthetic agent was used in our study. There was no correlation with the dose of infusion of vecuronium required to maintain a stable paralysis and the time of recovery in the study, $(\mathrm{p}=0.386)$. In our study, the vecuronium infusion was started at TOF response of one. The mean duration to reach TOF of 1 was $23.74 \pm 5.82$ minutes. Christoph Diefenbach, et $\mathrm{al}^{16}$, noted that the time of recovery from initial dose to $25 \%$ of the twitch control was $36 \pm 11$ min with fentanyl, midazolam and etomidate anesthesia. While W Buzello and G Noldge ${ }^{2}$ noted (dur 25\%) 26 minutes in with $\mathrm{N}_{2} \mathrm{O}+\mathrm{O}_{2}+$ Fentanyl anesthesia, where Vecuronium was given by continuous infusion for 201 minutes.

The heart rate and SBP/DBP showed mean rise of $3.00 \pm 3.84 /$ minute and $4.66 \pm 5.43 \mathrm{mmHg} / 2.53 \pm$ $3.68 \mathrm{mmHg}$ from preinduction value respectively. , Chaudhari LS, et al ${ }^{13}$ showed a mean change of $5.99+$ $2.67 \%$ and fall in blood pressure by $3.46+3.35 \%$ from the baseline value .(Pentazocin and atracurium based anesthesia) from the preinduction baselines values. The initial increase in heart rate and blood pressure correlates with the intubation response and TOF-1(Figure-2,3) is noted resulting in lighter planes of relaxation and a need for additional drug to maintain the depth of paralysis. Gradually the heart rate and blood pressure(Figure- 2,3) reached near the preinduction levels, once the infusion was started and stabilized to maintain a constant single TOF response. After stopping of infusion and during reversal again a rise in vital parameters were noted. Throughout our study, the heart rate did not decrease more than $20 \%$ from the preinduction value. As opposed to our study, EN Robertson, et $\mathrm{al}^{17}$ noted a statically significant drop in heart rate at 5 and 10 minutes after administration of vecuronium

The $\mathrm{p}$ value of systolic $(\mathrm{p}=0.00)$ and diastolic $(\mathrm{p}=0.12)$, blood pressure at 15 minutes after starting of infusion showed a significant difference from the preinduction values, while no significant difference is noted in heart rate $(\mathrm{p}=0.12)$ of the patients(figure-2,3). Fentanyl is known to decrease the heart rate, in our study fentanyl was given to patients every 40 minutes, so the heart rate showed less rise as compared to blood pressure in the study. Wiedra $\mathrm{JMKH}^{18}$ in a study of 320 patients showed that vecuronium did not influence heart rate and systolic blood pressure. Starting vecuronium infusion near to loading dose may decrease the initial hemodynamic instability. The mean spontaneous recovery time to recover from TOF of 1 to 3 was $12.4 \pm 3.63$ minutes (Figure-4). 54\% patients showed a recovery time between 11-15 minutes. The time of recovery is more 
in our study than that seen by Chaudhari LS, et $\mathrm{al}^{13}$ (as they have considered recovery till TOF-2) which was $\left(9.01 \pm 1.27 \mathrm{~min}\right.$.); but less as compared with results of $\mathrm{HH}$ Ali, et al ${ }^{14}$ (13.8 minutes) (25-75\% recovery time).

KL Gordan and CS Reilly ${ }^{19}$, noted a recovery time of $11.3 \pm 2$ minutes in the vecuronium infusion group. The correlation between Recovery time and duration of infusion is 0.36 (Figure-5)and it is significant as $p>0.05$ (i.e. 0.02), (Figure-5). The recovery time was 19 minutes in 57 years male patient received infusion for 145 minutes, while 18 minutes in 45 years female where infusion was given for 145 minutes increases if the infusion is given for longer duration, which is often noticed in ICU set-up. In the study done by Prielipp RC, et $\mathrm{al}^{20}$, recovery time averaged $387 \pm 163$ minutes where 30 patients received vecuronium infusion for mean duration of $66 \pm 12$ hours in ICU.W $\bar{W}$ S Beattie, et $\mathrm{al}^{\mathbf{2 1}}$ predicted that vecuronium induced blockade would be reversed faster in procedures lasting less than three hours or in young patients and also gave an equation for vecuronium reversal (time in minutes) $=-7.25+0.284$ (age in years) +0.12 (duration).

In our study, the longest recovery period of 28 minutes was seen in a patient who was over weight $(88$ $\mathrm{kg}$ ) and elderly (64 years) as well. AE Schwartz, et $\mathrm{al}^{22}$ proved that time to recovery from neuromuscular blockade was longer in obese patients $(93.4 \pm 13.9 \mathrm{~kg})$ as opposed to non-obese patients $(60.9 \pm 12.3$ $\mathrm{kg}$ ).Cynthia A Lien, et $\mathrm{al}^{23}$ and De Almeida Mc, et $\mathrm{al}^{24}$ concluded that an anesthetist should expect the action of vecuronium to be prolonged in elderly surgical patients. The altered pharmacokinetics and age related changes in renal and hepatic function prolonged the recovery time.

The quality of relaxation was judged by surgical the team (Table-6). It was a subjective assessment with lots of individual variability. Twenty-seven patients $(54 \%)$ had a good relaxation, while adequate was seen in $20(40 \%)$ patients. Only in 3 patients $(6 \%)$ the relaxation was poor. Patients were then monitored in PostAnesthesia Care Unit and after confirming normal hemodynamic status and adequate muscle tone, patients were shifted to respective wards. All patients were stable hemodynamically Fawcett $\mathrm{W}$, et $\mathrm{al}^{25}$ found that the postoperative recurarisation was $24 \%$ in vecuronium infusion group as compared to bolus group it was it was $12 \%$. However, in their study difference could not be made clinically in the two groups.

\section{Figures}

Fig- 1 Mean Dose in $\mu \mathrm{g} / \mathrm{kg} / \mathrm{hr}$ of Vecuronium given by continuous Infusion in respective age groups Fig-2 Event Wise Variability In Heart Rate
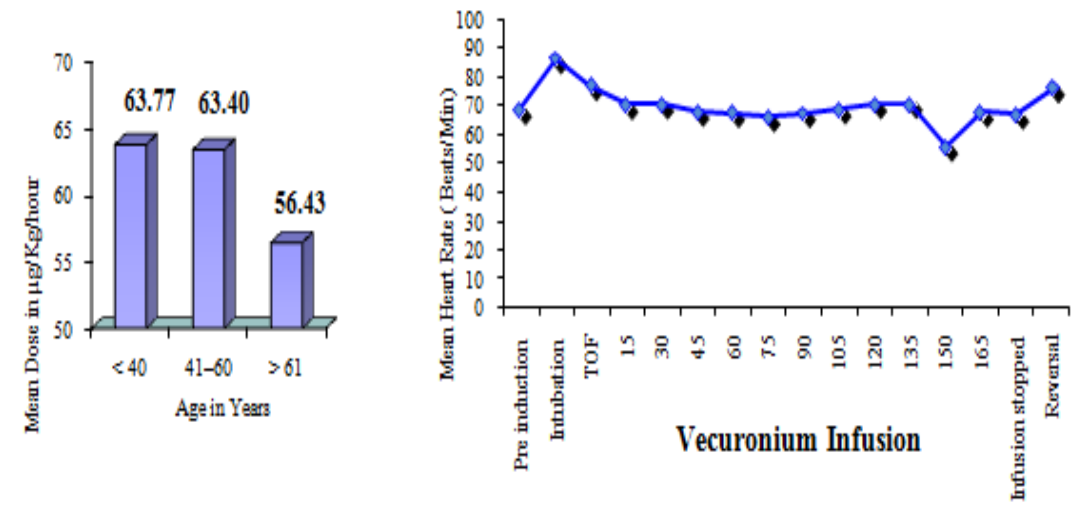

FIG- 3 Event Wise Variability In Heart Rate

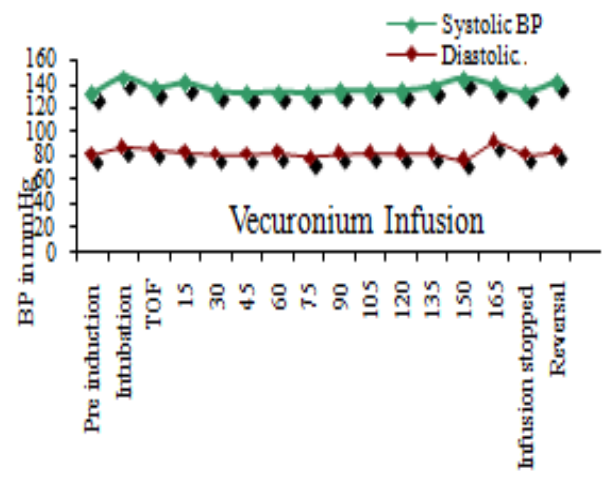

FIG. 4 Frequency Distribution 0 f Recovery Time

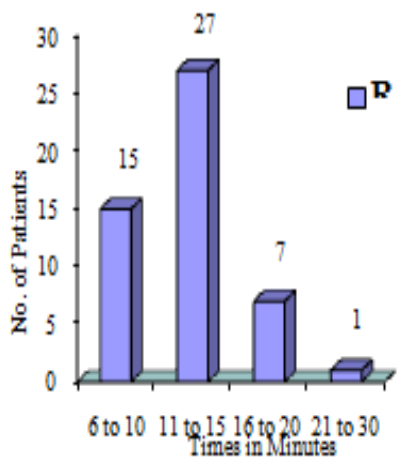



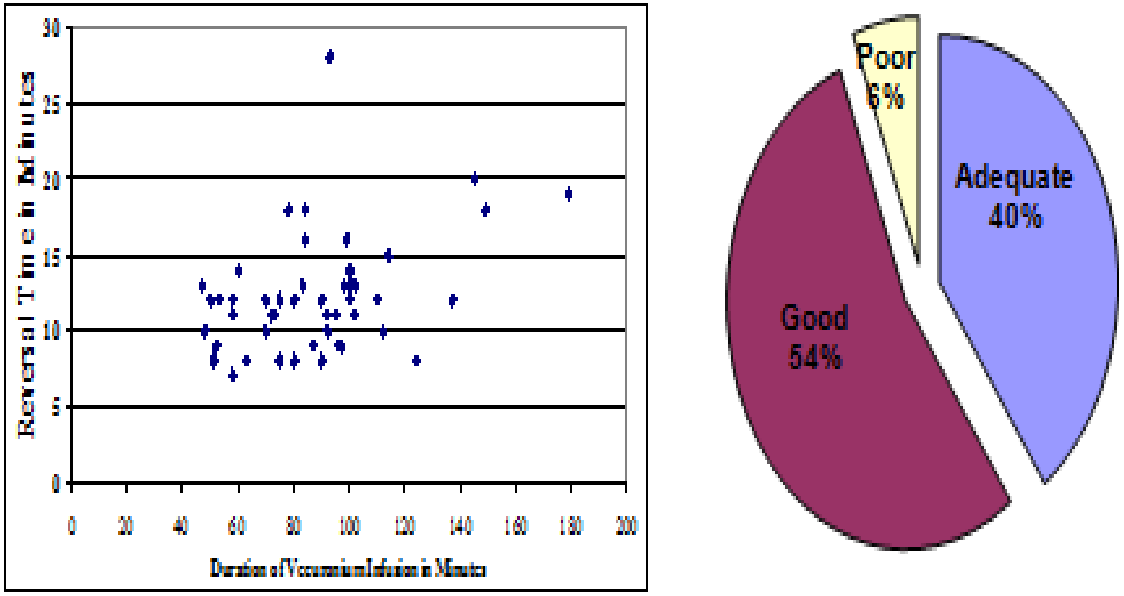

\section{Conclusion}

So we conclude that the vecuronium by continuous infusion technique provides an adequate level of relaxation, hemodynamic stability and prompt recovery without any side effects. The future prospective to the study would be computerized drug delivery system permitting self adjustment of the rate of infusion with respect to the TOF response. The better way of administrating short to intermediate acting muscle relaxants would be computerized analysis of patient's plasma concentration of the drug and auto-adjustment of the infusion rate accordingly, by the system.

\section{References}

[1]. Matias Vested Madsen, Susanne Scheppan, Peter Kissmeyer, Emilie Mørk, Jacob Rosenberg,Mona Ring Gätke. Neuromuscular blockade for improvement Of surgical conditions during laparotomy: Protocol for a randomised study. Dan Med J 62/10 , October 2015 .

[2]. W Buzello and G Noldge. Repititive administration of pancuronium and vecuronium (Org NC 45, Norcuron) in patients undergoing long lasting operation. British Journal Anaesthesiology. 1982; 54 : 1151-1156.

[3]. Savage D, Sleigh T, Carlyle I. The emergence of ORG NC 45, 1-[2 beta, 3 beta, 5 alpha, 16 beta, 17 beta-3, 17-bis(acetyloxyl)-2(1-piparidinyl)-androstan-16-yl]-1-methylpiperidinium bromide, from the pharmacokinetic series. British Journal Anaesthesiology. 1980; 52(suppl 1) : 3-9.

[4]. Cannon JE, Fahey MR, Castagnoli KP, Furuta T, Canfell PC, Sharma M, Miller RD. Continuous infusion of vecuronium : the effect of anesthetic agents. Anesthesiology. 1987 Oct; 67(4) : 503-506.

[5]. Alan F. Merry, FANZCA, ${ }^{1,2}$ Jeffrey B. Cooper, PhD, ${ }^{3}$ Olaitan Soyannwo, MMed, ${ }^{4}$ Iain H. Wilson, FRCA, ${ }^{5}$ and John H. Eichhorn, $\mathrm{MD}^{6}$ International Standards for a Safe Practice of Anesthesia 2010 Can J hn Anaesth. 2010 Nov; 57(11): 1027-1034.

[6]. White PF. Use of continuous infusion versus intermittent bolus administration of fentanyl or ketamine during outpatient anesthesia. Anesthesiology. 1983; $59: 294-300$.

[7]. Ausems ME, Vuyk J, Hug CC and Stanski DR. Comparison of a computer-assisted infusion versus intermittent bolus administration of alfentanil as a supplement to nitrous oxide for lower abdominal surgery. Anesthesiology. 1988; 68:851-861.

[8]. Foldes FF, McNall PG, Borrego-Henjosa JM. Succinylcholine, A approach to muscle relaxation in Anesthesiology. N Engl J Med. $1952 ; 247: 596-600$.

[9]. Eriksson LI, Staun P, Cederholm I, Zennmarken C, Lofstrom JB. Experience with vecuronium during long lasting surgery. Acta Anaesthesiol Scand. 1988; $32: 619-622$.

[10]. Mirakhur RK, Ferres CJ. Muscle relaxation with an infusion of vecuronium. European Journal of Anaesthesiology. 1984; 1 : 353359 .

[11]. d'Hollander A, Massaux F, Nevelsteen M, Agoston. Age dependent dose- response relationship of Org NC 45 in anesthesized patient. British Journal Anaesthesia. 1982; $54: 653-657$.

[12]. Cynthia A Lien, Richard S Matteo, Eugene Ornstein, Arthur E Schwartz and Jaime Diaz. Distribution, elimination, and action of vecuronium in the elderly. Anesthesia-Analgesia. 1991; $73: 39-42$.

[13]. Chaudhari LS, Shetty AN, Buddhi M, Krishnan GA. Comparison of continuous infusion of vecuronium and atracurium in midline and paramedian laprotomies. J Postgrad Med. 1999; 45 : 5-9.

[14]. HH Ali, JJ Saverese, PB Embree, SJ Basta, RG Stout, LH Bottros and JN Weakly. Clinical pharmacology of mivacurium chloride (BW B1090U) infusion : comparison with vecuronium and atracurium. British Journal of Anaesthesia. 1988; 61 : 541-546.

[15]. J Swen, Peter J Gencarelli and HWJ Koot. Vecuronium infusion dose requirement during fentanyl and halothane anesthesia in humans. Anesthesia-Analgesia. 1985; $64: 411-414$.

[16]. Christoph Diefenbach, Hermann Mellinghoff, Stefan Grond and Walter Buzello. Atracurium and Vecuronium : Repeated bolus injection versus infusion. Anesthesia-Analgesia. 1992; $74: 519-522$.

[17]. EN Robertson, LHDJ Booij, RJ Fragen and JF Crul. Clinical comparison of atracurium and vecuronium (org NC 45). British Journal of Anaesthesia. 1983; $55: 125-129$.

[18]. Wiedra JMKH. Hemodynamic effects of vecuronium. British Journal of Anaesthesia. 1989; 62: 194-198. 
[19]. KL Gordan and CS Reilly. Recovery of neuromuscular function after infusion or intermittent bolus doses of atracurium or vecuronium. British Journal of Anaesthesia. 1989; $62: 269-273$.

[20]. Prielipp RC, Coursin DB, Scuderi PE, Bowton DL, Ford SR, Cardenas VJ Jr, Vender J, Howard D, Casale EJ, Murray MJ. Comparison of the infusion requirements and recovery profiles of vecuronium and cisatracurium $51 \mathrm{~W} 89$ in intensive care unit patients. Anesthesia-Analgesia. 1995 July; 81(1) : 3-12.

[21]. WS Beattie, DN Buckley and JB Forrest. Continuous infusions of atracurium and vecuronium, compared with intermittent boluses of pancuronium : dose requirements and reversal. Canadian J Anesthesia. 1992; 39 : 925-931.

[22]. AE Schwartz, RS Matteo, E Ornstein, JD Halevy and J Diaz. Pharmacokinetics and pharmacodynamics of vecuronium in the obese surgical patient dis wt. Anesthesia-Analgesia. 1992; $74: 515-518$.

[23]. De Almeida Mc, Latorre F, Gervais Hw, Kleeman PP. The effects of age on onset and recovery from atracurium, rocuronium, and vecuronium blockade. Anaesthesia. 1996; 45 : 903-906.

[24]. Fawcett W, Cashman JN. Residual curarisation following vecuronium or atracurium by bolus or infusion. British Journal of Anaesthesia. 1994; $66:$ A-153. 